\title{
EFEKTIVITAS MODEL PROJECT BASED LEARNING UNTUK MENINGKATKAN HASIL BELAJAR MAHASISWA STKIP PGRI PONTIANAK
}

\author{
Chandra Lesmana \\ STKIP PGRI Pontianak \\ chandralesmana87@gmail.com \\ Amat Jaedun \\ Universitas Negeri Yogyakarta \\ zaedun0808@gmail.com
}

\begin{abstract}
Abstrak
Penelitian ini bertujuan untuk: (1) menguji keefektifan penerapan model PjBL di Program Studi PTIK STKIP PGRI Pontianak pada mata kuliah Pemrograman Visual 1 dalam meningkatkan hasil belajar mahasiswa. (2) menguji kemungkinan implementasi model pembelajaran PjBL di Program Studi PTIK STKIP PGRI Pontianak. Penelitian ini mengunakan jenis penelitian quasi experiment. Desain dalam penelitian ini menggunakan posttest control group design dengan kelompok non ekuivalen. Populasi dalam penelitian ini adalah seluruh mahasiswa semester 4 dari Program Studi PTIK STKIP PGRI Pontianak. Dalam penelitian ini pengumpulan data dilakukan setelah perlakuan (posttest). Data posttest dianalisis secara deskriptif dengan Anova untuk mengetahui perbedaan antara kelompok eksperimen dan kelompok kontrol. Hasil pengujian hipotesis yang menyatakan bahwa terdapat perbedaan hasil belajar antara mahasiswa yang diajar dengan pembelajaran PjBL dibandingkan mahasiswa yang diajarkan dengan pembelajaran konvensional dengan metode tutorial.
\end{abstract}

Kata kunci: efektivitas, project based learning, TIK

\section{THE EFFECTIVENESS PROJECT-BASED LEARNING MODEL TO IMPROVE STUDENT'S LEARNING ACHIEVEMENT OF STKIP PGRI PONTIANAK}

\begin{abstract}
This research aimed at: (1) testing the effectiveness of PjBL at ICT Education Study Program in Visual Programming 1 subject to improve the student's learning achievement and, (2) testing the possibility the implementation of PjBL learning model at ICT study program of STKIP PGRI Pontianak. This research used quasi-experimental research design. The design used at this research was posttest control group design with non-equivalent group. Data collecting techniques used at this research were questionnaire, observation and project assessment. In this research, the data collecting was conducted after the treatment (posttest). The posttest data was analyzed descriptively by using Anova formula to find out the difference between the experimental groups and controlled group. The hypotheses testing result shows that there are learning achievement difference between the students who leaner by using PjBL model and the conventional one.
\end{abstract}

Keywords: effectiveness, project-based learning, ICT

\section{PENDAHULUAN}

Pasal 3 UU Nomor 20 Tahun 2003 tentang Sistem Pendidikan Nasional menjelaskan bahwa tujuan pendidikan nasional adalah mengembangkan potensi mahasiswa agar menjadi manusia yang beriman, dan bertaqwa kepada Tuhan Yang Maha Esa, berakhlak mulia, sehat, berilmu, cakap, kreatif, mandiri, dan menjadi warga negara yang demokratis serta bertanggung jawab. Bertitik tolak dari dasar, fungsi dan tujuan pendidikan nasional tersebut menjadi jelas bahwa manusia 
Indonesia yang hendak dibentuk melalui proses pendidikan bukan sekedar manusia yang berilmu pengetahuan semata tetapi sekaligus membentuk manusia Indonesia yang berkepribadian sebagai warga Negara Indonesia yang demokratis dan bertanggung jawab.

Pembelajaran pada hakikatnya merupakan kegiatan yang dilakukan oleh peserta didik yang berakibat terjadinya perubahan pada diri pribadinya. Prinsip ini mengandung arti bahwa yang harus diutamakan adalah kegiatan belajar peserta didik dan bukannya sesuatu yang diberikan kepada peserta didik. Pendidikan memiliki 3 (tiga) jenis yaitu pendidikan formal, non-formal, dan informal. Jalur pendidikan sekolah meliputi pendidikan dasar, pendidikan menengah, dan pendidikan tinggi.

Keberadaan pendidikan tinggi memegang peran yang strategis. Berdasarkan UU RI No 12 Tahun 2012 Tentang Pendidikan Tinggi Pasal 1 angka 2 menyatakan bahwa Pendidikan Tinggi adalah jenjang pendidikan setelah pendidikan menengah yang mencakup program diploma, program sarjana, program magister, program doktor, dan program profesi, serta program spesialis, yang diselenggarakan oleh perguruan tinggi berdasarkan kebudayaan bangsa Indonesia. Hal ini berarti bahwa pendidikan tinggi mempersiapkan sumberdaya manusia yang cerdas, handal, kreatif dan memiliki keunggulan di bidang Ilmu dan Teknologi (IPTEK) dan kualitas Iman dan Taqwa (IMTAQ) yang kokoh.

Data dari Dinas Pendidikan Kalimantan Barat Tahun 2008 mengenai pendidikan tinggi menunjukan bahwa Provinsi Kalimantan Barat baru memiliki 1 Universitas Negeri, 1 Politeknik Negeri dan 1 Sekolah Tinggi Agama Islam Negeri (STAIN) serta 33 Universitas / Sekolah Tinggi / Akademi Swasta. Salah satu penyelenggara pendidikan tinggi swasta di Kalimantan Barat adalah Sekolah Tinggi Keguruan dan Ilmu Pendidikan Persatuan Guru Republik Indonesia (STKIP PGRI) Pontianak.

STKIP PGRI Pontianak didirikan oleh PGRI Daerah Kalimantan Barat pada tanggal 25 Juli 1981. Pada tahun akademik 1981/1982 STKIP PGRI Pontianak langsung beroperasi dengan mulai melaksanakan perkuliahan sebagaimana layaknya sebuah perguruan tinggi. Badan penyelenggara yang melakukan pembinaan secara operasional adalah Yayasan Pembina Lembaga Pendidikan (YPLP) PGRI yang berkedudukan di Jakarta, dan sudah disyahkan keberadaannya dengan Akta Notaris Muhammad Ali No.21 tanggal 31 Maret 1980 daftar Berita Negara RI tanggal 26 Desember 1986 No.103 tambahan No.39. Kedudukan PGRI adalah sebagai Pembina YPLP-PGRI sesuai dengan AD/ART YPLP-PGRI, sebagai unsur pelaksana di daerah adalah Yayasan Pembina Lembaga Perguruan Tinggi (YPLP-PT) PGRI Pontianak Akta No.76 Notaris Mochamad Damiri tanggal 17 Maret 1982 di Pontianak.

Salah satu mata kuliah yang mengintegrasikan kemampuan kognitif, afektif, dan psikomotorik adalah Pemrograman Visual 1. Berdasarkan hasil observasi lapangan untuk mata kuliah Pemrograman Visual 1 masih berfokus pada ranah kognitif dan tidak sepenuhnya masuk dalam ranah afektif dan psikomotorik. Hal tersebut dapat dilihat dari hasil belajar yang dicapai mahasiswa masuk kedalam kategori cukup.

Model pembelajaran yang kurang efektif dapat dilihat dari beberapa faktor diantaranya adalah: (1) mahasiswa tidak berinteraksi aktif selama proses pembelajaran; (2) pengajar belum memberi kesempatan yang optimal kepada mahasiswa untuk mengembangkan kreativitas pada saat proses pembelajaran; (3) pengajar belum memberikan inovasi terhadap model pembelajaran yang akan diterapkan; (4) pengajar belum mampu meningkatkan motivasi belajar mahasiswa; (5) pengajar belum membuat mahasiswa menjadi lebih aktif dan berhasil memecahkan masalah-masalah yang kompleks; (6) pengajar belum mampu meningkatkan kolaborasi antar mahasiswa; (7) pengajar belum mampu mendorong peserta didik untuk mengembangkan dan keterampilan dalam proses pembelajaran. Oleh karena itu model pembelajaran yang diterapkan saat ini harus dirubah ke model pembelajaran yang efektif seperti model pembelajaran yang dapat memberikan pengalaman belajar yang lebih menarik dan bermakna bagi mahasiswa, model pembelajaran yang dapat mendorong mahasiswa untuk dapat membuat keputusan dan membuat kerangka kerja, serta pemecahan masalah yang kompleks dalam proses pembelajaran. Penerapan model pembelajaran 
yang efektif dapat meningkatkan hasil belajar mahasiswa.

Pembelajaran yang efektif dapat terwujud bila proses pembelajaran dapat berlangsung secara lancar, terarah dan sesuai dengun tujuan pembelajaran. Kriteria proses pembelajaran yang efektifterdiri dari:(1) proses pembelajaran mampu mengembangkan konsep generalisasi serta bahan abstrak menjadi hal yang jelas dan nyata; (2) proses pembelajaran mampu melayani perkembangan belajar peserta didik yang berbeda-beda; (3) proses belajar mengajar melibatkan peserta didik secara aktif dalam pembelajaran sehingga proses pembelajaran rnampu mencapai tujuan sesuai program yang telah ditetapkan (Rusyan. T 1989: 12).

Beberapa model pembelajaran yang efektif menurut Rusman (2012, p.115) diantaranya adalah model Contextual Teaching Learning (CTL), Inquiry, Problem Based Learning, Problem Solving, dan Project Based Learning. Model-model pembelajaran tersebut berusaha untuk meningkatkan kemampuan mahasiswa untuk mengenali masalah, merumuskan masalah, mencari solusi dan menguji jawaban sementara atas suatu masalah/pertanyaan dengan melakukan penyelidikan (menemukan fakta-fakta melalui penginderaan), pada akhirnya dapat menarik kesimpulan dan menyajikannya secara lisan maupun tulisan.

Berdasarkan hasil observasi lapangan yang telah dilakukan, model pembelajaran efektif yang cocok untuk meningkatkan hasil belajar mahasiswa dalam mata kuliah Pemrograman Visual 1 adalah model pembelajaran Project Based Learning (PjBL). PjBL dipilih karena sesuai dengan karakteristik mata kuliah tersebut. Karakteristik mata kuliah Pemrograman Visual 1 mencakup pembahasan tentang manajemen project, tipe data, alur algorimta runtunan, percabangan dan perulangan. Disamping itu juga dibahas teknik pemrograman dengan Visual Componen Library (VCL). Materi pembelajaran diarahkan untuk mengembangkan pengetahuan dan kemampuan mahasiswa dalam pembuatan program aplikasi sederhana hingga aplikasi yang lebih kompleks.

Menurut Jonassen (1997), PjBL menggunakan pendekatan konstruktivistik untuk instruksi, dengan berfokus khusus pada dunia nyata. Orientasi PjBL lebih mengarah pada kesempatan belajar berbasis penyelidikan yaitu pengalaman terstruktur yang didasarkan pada keyakinan bahwa pembelajaran terjadi ketika individu diminta untuk menyelidiki tentang masalah tersebut. Brears, MacIntyre, dan O'Sullivan (2011) menjelaskan bahwa proses penyelidikan bisa dimulai dengan refleksi diri dan evaluasi. Brears (2011) mencatat pentingnya tiga aspek yang membantu mahasiswa dalam pemecahan masalah yaitu kelompok kerja kolaboratif, penekanan pada analisis dan evaluasi, dan refleksi tambahan (praktik). Dalam konteks ini, PjBL diterapkan sebagai salah satu model pembelajaran yang paling menarik. PjBL mendorong mahasiswa untuk menjadi seseorang yang mandiri, menghargai orang lain dari sudut pandang yang berbeda dan menjadi pemikir kritis, serta mengembangkan keterampilan kerja tim, sehingga proses pembelajaran yang dilakukan mahasiswa dapat mencapai hasil yang komprehensif. Adapun karakteristik pembelajaran berbasis proyek adalah mahasiswa menyelidiki ide-ide penting dan bertanya, mahasiswa menemukan pemahaman dalam proses menyelidiki, sesuai dengan kebutuhan dan minatnya, mahasiswa dapat menghasilkan produk dan berpikir kreatif, kritis dan terampil menyelidiki, mahasiswa dapat menyimpulkan materi, serta mahasiswa dapat menghubungkan dengan masalah dunia nyata, otentik dan isu-isu.

Berdasarkan uraian latar belakang di atas, penelitian ini dilakukan dengan menerapkan model Project Based Learning untuk melihat peningkatan hasil belajar mahasiswa STKIP PGRI Pontianak Program Studi PTIK pada mata kuliah Pemograman Visual 1.

\section{METODE PENELITIAN}

Pendekatan yang digunakan dalam penelitian ini adalah pendekatan kuantitatif. Semua data yang diperoleh dapat dirangkum, dianalisis dan diolah secara kuantitatif. Metode yang digunakan dalam penelitian ini adalah metode quasi esperimental research.

Khususnya untuk penelitian kualitatif, waktu dan tempat penelitian perlu dituliskan secara jelas (untuk penelitian kuantitatif, juga perlu).Penelitian dilaksanakan pada semester 
Tabel 2. Hasil Pengujian Hipotesis (One-Way Anova)

ANOVA

Nilai

\begin{tabular}{|c|c|c|c|c|c|}
\hline & Sum of Squares & df & Mean Square & $\mathbf{F}$ & Sig. \\
\hline Between Groups & 1020.086 & 3 & 340.029 & 4.138 & .008 \\
\hline Within Groups & 11339.069 & 138 & 82.167 & & \\
\hline Total & 12359.155 & 141 & & & \\
\hline
\end{tabular}

genap (IV) tahun pelajaran 2013 / 2014. Penelitian ini dilakukan di Prodi Pendidikan TIK STKIP PGRI Pontianak, Kalimantan Barat

Populasi dalam penelitian ini adalah seluruh mahasiswa semester 4 dari Program Studi PTIK STKIP PGRI Pontianak. Dalam pemilihan kelas pada penelitian ini menggunakan teknik Random Assigment dengan Simple Random dari setiap populasi semester 4 Program Studi PTIK STKIP PGRI Pontianak tahun angkatan 2013/2014 dan dihasilkan 4 kelas yaitu kelompok eksperimen (C Pagi dan B Sore) serta kelompok kontrol (B Pagi dan A Sore). Dalam pemilihan sampel kelas digunakan Intax Sample dengan seluruh anggota kelas yang berjumlah 36 mahasiswa.

Rancangan atau desain dalam penelitian ini menggunakan posttest control group design dengan kelompok non ekuivalen. Tujuan penggunaan kelompok eksperimen dan kelompok kontrol pada penelitiaan ini untuk melihat perbedaan efek perlakuan yang berupa hasil belajar. Rancanga eksperimen dapat dilihat pada tabel 1 .

Tabel 1. Posttest Control Group Design

\begin{tabular}{ccc}
\hline Perlakuan & Posttest & Kelompok \\
\hline $\mathrm{A}$ & $\mathrm{X}_{1}$ & Eksperimen \\
$\mathrm{B}$ & $\mathrm{X}_{2}$ & Kontrol \\
\hline
\end{tabular}

Dalam penelitian ini, untuk mengukur hasil belajar dilakukan dengan tes hasil belajar secara teoritis. Tes tertulis untuk mengukur pencapaian hasil belajar teori yang mencakup ranah kognitif dari penguasaan konsep yang sederhana sampai kompleks, adapun tahapan dari instrumen penelitian dalam penelitian ini yaitu: (1) Bentuk instrumen, (2) Kisi - kisi instrumen, (3) Validasi instrumen, (4) Teknik pengumpulan data.

Dalam penelitian ini pengumpulan data dilakukan setelah perlakuan (post test).
Data nilai setelah pembelajaran (post test) akan dianalisis secara deskriptif dan dicari selisihnya untuk mengetahui peningkatan hasil pembelajaran. Selisih nilai inilah yang akan menentukan analisis untuk menguji hipotesis yang diajukan dengan cara uji komparasi.

\section{HASIL PENELITIAN DAN PEMBAHASAN}

\section{Hasil Penelitian Penilaian Kognitif}

Hasil penelitian penilaian kognitif yang telah dilakukan dapat dilihat pada tabel uji One-Way Anova dan tabel uji lanjut (Post Hoc).

Berdasarkan Tabel 2 dapat dilihat bahwa nilai kuadrat antar kelompok sebesar 1020,086 dengan rata-rata kuadrat 340,029. Jumlah kuadrat diantara kelompok 11339,069 dengan rata-rata kuadrat 82,167. Besar $F$ hitung adalah 4,138 dengan signifikan 0,001. Dengan ketentuan yang digunakan apabila $\mathrm{F}$ hitung lebih besar dari $\mathrm{F}$ tabel maka hipotesis diterima, dari hasil penelitian diperoleh $\mathrm{F}$ hitung 4,138 sedangkan nilai $\mathrm{F}$ tabel dengan taraf kesalahan $5 \%$ adalah 2,67. Dari perbandingan nilai tersebut didapatkan bahwa nilai $\mathrm{F}$ hitung $>\mathrm{F}$ tabel yaitu 4,138>2,67 sehingga hipotesis diterima. Sedangkan untuk nilai taraf signifikan dengan hasil $\alpha=0,008<0,05$. Maka dapat disimpulkan penerapan model pembelajaran PjBL lebih efektif dalam meningkatkan hasil belajar mahasiswa di Program Studi PTIK STKIP PGRI Pontianak dibanding model pembelajaran konvensional dengan metode tutorial. Untuk mengetahui kelas mana yang berbeda makan dilakukan uji lanjut atau post hoc.

Dari Tabel 3, maka didapatkan bahwa kelas yang memiliki perbedaan yang signifikan adalah kelompok eksperimen A dengan kelompok kontrol B dengan selisih nilai 7,38399 dan signifikansi 0,005, dan kelompok kontrol B dengan kelompok eksperimen A 
Tabel 3 Hasil Uji Lanjut (Post Hoc) Turkey HSD

Multiple Comparisons

Nilai

TukeyHSD

\begin{tabular}{|c|c|c|c|c|c|c|}
\hline \multirow{2}{*}{ (I) Kode } & \multirow{2}{*}{ (J) Kode } & \multirow{2}{*}{ Mean Difference (I-J) } & \multirow{2}{*}{$\begin{array}{l}\text { Std. } \\
\text { Error }\end{array}$} & \multirow{2}{*}{ Sig. } & \multicolumn{2}{|c|}{$\begin{array}{l}\text { 95\% Confidence } \\
\text { Interval }\end{array}$} \\
\hline & & & & & $\begin{array}{l}\text { Lower } \\
\text { Bound }\end{array}$ & $\begin{array}{l}\text { Upper } \\
\text { Bound }\end{array}$ \\
\hline \multirow[t]{3}{*}{ Eksp A } & Eksp B & 2.50000 & 2.13655 & .647 & -3.0563 & 8.0563 \\
\hline & Kontrol A & 4.41667 & 2.13655 & .169 & -1.1397 & 9.9730 \\
\hline & Kontrol B & $7.38399^{*}$ & 2.16774 & .005 & 1.7465 & 13.0214 \\
\hline \multirow[t]{3}{*}{ Eksp B } & Eksp A & -2.50000 & 2.13655 & .647 & -8.0563 & 3.0563 \\
\hline & Kontrol A & 1.91667 & 2.13655 & .806 & -3.6397 & 7.4730 \\
\hline & Kontrol B & 4.88399 & 2.16774 & .114 & -.7535 & 10.5214 \\
\hline \multirow[t]{3}{*}{ Kontrol A } & Eksp A & -4.41667 & 2.13655 & .169 & -9.9730 & 1.1397 \\
\hline & Eksp B & -1.91667 & 2.13655 & .806 & -7.4730 & 3.6397 \\
\hline & Kontrol B & 2.96732 & 2.16774 & .521 & -2.6701 & 8.6048 \\
\hline \multirow[t]{3}{*}{ Kontrol B } & Eksp A & $-7.38399^{*}$ & 2.16774 & .005 & -13.0214 & -1.7465 \\
\hline & Eksp B & -4.88399 & 2.16774 & .114 & -10.5214 & .7535 \\
\hline & Kontrol A & -2.96732 & 2.16774 & .521 & -8.6048 & 2.6701 \\
\hline
\end{tabular}

*. The mean difference is significant at the 0.05 level.

Tabel 4. Hasil Pengujian Hipotesis (One-Way Anova)

ANOVA

Penilaian_Proyek

\begin{tabular}{|c|c|c|c|c|c|}
\hline & Sum of Squares & df & Mean Square & $\mathbf{F}$ & Sig. \\
\hline Between Groups & 1142.938 & 3 & 380.979 & 5.755 & .001 \\
\hline Within Groups & 9136.111 & 138 & 66.204 & & \\
\hline Total & 10279.049 & 141 & & & \\
\hline
\end{tabular}

dengan selisih nilai $-7,38399$ dan signifikansi 0,005 .

\section{Hasil Penelitian Penialain Proyek}

Hasil penelitian penilaian proyek yang telah dilakukan dapat dilihat pada tabel 4 uji One-Way Anova dan tabel 5 uji lanjut (Post Hoc).

Berdasarkan Tabel 4 dapat dilihat bahwa untuk nilai taraf signifikan penilaian proyek dengan hasil $\alpha=0,001<0,05$. Maka dapat disimpulkan penerapan model pembelajaran PjBL lebih efektif dalam penilaian tugas proyek mahasiswa di Program Studi PTIK STKIP PGRI Pontianak dibanding model pembelajaran konvensional dengan metode tutorial. Untuk mengetahui kelas mana yang berbeda maka dilakukan uji lanjut atau post hoc.

Dari Tabel 5, maka didapatkan bahwa kelas yang memiliki perbedaan yang signifikan adalah kelompok eksperimen A dengan kelompok kontrol B dengan selisih nilai 6,11 dan signifikansi 0,011, kelompok eksperimen $\mathrm{B}$ dengan kelompok kontrol $\mathrm{B}$ dengan selisih 7,08 dan signifikansi 0,002, kelompok kontrol $\mathrm{B}$ dengan kelas eksperimen A dengan selisih nilai $-6,11$ dan signifikansi 0,011 , dan kelompok kontrol B dengan kelas eksperimen B dengan selisih -7,08 dan signifikansi 0,002.

Pembelajaran PjBL efektif terhadap peningkatan hasil belajar mahasiswa STKIP PGRI Pontianak Program Studi PTIK 
Tabel 5 Hasil Uji Lanjut (Post Hoc) Turkey HSD Penilaian Proyek Multiple Comparisons

Nilai

TukeyHSD

\begin{tabular}{|c|c|c|c|c|c|c|}
\hline \multirow{2}{*}{ (I) Kode } & \multirow{2}{*}{ (J) Kode } & \multirow{2}{*}{ Mean Difference (I-J) } & \multirow{2}{*}{$\begin{array}{l}\text { Std. } \\
\text { Error }\end{array}$} & \multirow{2}{*}{ Sig. } & \multicolumn{2}{|c|}{$\begin{array}{l}\text { 95\% Confidence } \\
\text { Interval }\end{array}$} \\
\hline & & & & & $\begin{array}{l}\text { Lower } \\
\text { Bound }\end{array}$ & $\begin{array}{l}\text { Upper } \\
\text { Bound }\end{array}$ \\
\hline \multirow[t]{3}{*}{ Eksp A } & Eksp B & -.97222 & 1.91781 & .957 & -5.9597 & 4.0152 \\
\hline & Kontrol A & 3.75000 & 1.91781 & .210 & -1.2375 & 8.7375 \\
\hline & Kontrol B & $6.11111^{*}$ & 1.94581 & .011 & 1.0508 & 11.1714 \\
\hline \multirow[t]{3}{*}{ Eksp B } & Eksp A & .97222 & 1.91781 & .957 & -4.0152 & 5.9597 \\
\hline & Kontrol A & 4.72222 & 1.91781 & .071 & -.2652 & 9.7097 \\
\hline & Kontrol B & $7.08333 *$ & 1.94581 & .002 & 2.0230 & 12.1436 \\
\hline \multirow[t]{3}{*}{ Kontrol A } & Eksp A & -3.75000 & 1.91781 & .210 & -8.7375 & 1.2375 \\
\hline & Eksp B & -4.72222 & 1.91781 & .071 & -9.7097 & .2652 \\
\hline & Kontrol B & 2.36111 & 1.94581 & .619 & -2.6992 & 7.4214 \\
\hline \multirow[t]{3}{*}{ Kontrol B } & Eksp A & $-6.11111^{*}$ & 1.94581 & .011 & -11.1714 & -1.0508 \\
\hline & Eksp B & $-7.08333^{*}$ & 1.94581 & .002 & -12.1436 & -2.0230 \\
\hline & Kontrol A & -2.36111 & 1.94581 & .619 & -7.4214 & 2.6992 \\
\hline
\end{tabular}

*. The mean difference is significant at the 0.05 level

Semester empat yang merupakan kelompok eksperimen. Hal ini dapat dilihat dengan data deskriptif dan uji hipotesis. Berdasarkan hasil analisis data deskriptif dengan statistik bahwa dapat diketahui terdapat perbedaan antara nilai posttest pada kelompok eksperimen dan kelompok kontrol. Pada kelompok eksperimen yang diberikan treatment berupa pembelajaran $\mathrm{PjBL}$ mendapatkan hasil rata-rata nilai kelompok eksperimen A adalah 44,9722, dan kelompok eksperimen B adalah 42,4722. Sedangkan kelompok kontrol mendapatkan hasil rata-rata nilai kelompok kontrol A adalah 40,5556, dan kelompok kontrol B adalah 37,5882. Jadi antara kelompok eksperimen dan kelompok kontrol memiliki kemampuan yang berbeda.

Dalam pembelajaran PjBL pada penelitian ini menggunakan penilaian proyek untuk melihat dan meningkatkan pengetahuan dan keterampilan mahasiswa dalam merencanakan kegiatan proyek sampai dengan membuat proyek aplikasi. Berdasarkan hasil analisis data deskriptif penilaian tugas proyek dengan statistik bahwa dapat diketahui terdapat perbedaan antara nilai tugas proyek pada kelompok eksperimen dan kelompok kontrol. Pada penilaian proyek kelompok eksperimen yang diberikan treatment berupa pembelajaran PjBL mendapatkan hasil rata-rata nilai kelompok eksperimen A adalah 73,61, dan kelompok eksperimen B adalah 74,58. Sedangkan penilaian proyek kelompok kontrol mendapatkan hasil rata-rata nilai kelompok kontrol Aadalah 69,8611, dan kelompok kontrol B adalah 67,50. Jadi dapat disimpulkan bahwa penilaian proyek antara kelompok eksperimen dan kelompok kontrol memiliki kemampuan yang berbeda. Sedangkan untuk melihat apakah dalam penilaian proyek kelompok eksperimen dan penilaian proyek pada kelompok kontrol mempumyai perbedaan yang signifikan dapat menggunakan analisis One-Way Anova pada penilaian proyek yang diberikan pada mahasiswa STKIP PGRI Pontianak Studi Pendidikan Teknologi Informasi dan Komputer Semester empat. Berdasarkan hasil analisis One-Way Anova dapat dilihat bahwa untuk nilai taraf signifikan penilaian proyek dengan hasil $\alpha=0,001<0,05$. Maka dapat disimpulkan penerapan model pembelajaran PjBL lebih efektif dalam penilaian tugas 
proyek mahasiswa di Program Studi PTIK STKIP PGRI Pontianak dibanding model pembelajaran konvensional dengan metode tutorial. Sedangkan untuk mengetahui kelas mana yang berbeda maka dilakukan uji lanjut atau post hoc. Hasil uji lanjut maka didapatkan bahwa kelas yang memiliki perbedaan yang signifikan adalah kelompok eksperimen A dengan kelompok kontrol B dengan selisih nilai 6,11 dan signifikansi 0,011, kelompok eksperimen B dengan kelompok kontrol B dengan selisih 7,08 dan signifikansi 0,002, kelompok kontrol B dengan kelas eksperimen A dengan selisih nilai $-6,11$ dan signifikansi 0,011, dan kelompok kontrol B dengan kelas eksperimen B dengan selisih -7,08 dan signifikansi 0,002.

Pembelajaran PjBL dapat didukung dengan aspek penilaian keterampilan (psikomotorik). Penilaian keterampilan (psikomotorik) pada penelitian ini melalui observasi yang dilakukan oleh pengajar berupa lembar observasi yang digunakan untuk melihat keterampilan mahasiswa secara individu melalui kerja proyek. Hasil analisis keterampilan mahasiswa dapat dilihat dengan persentase penilaian psikomotorik yang dapat diperoleh pada kelompok eksperimen A dengan tingkat keterampilan Sangat Terampil $42 \%$ dari seluruh angket. Jawaban Terampil dengan persentase $33 \%$ dari seluruh angket. Jawaban Kurang Terampil dengan persentase $25 \%$ dari seluruh angket. Sehingga dapat disimpulkan bahwa untuk penilaian psikomotorik kelompok eksperimen A tergolong Sangat Terampil. Untuk kelompok eksperimen B dapat diketahui bahwa hasil penilaian psikomotorik dengan tingkat keterampilan Sangat Terampil 44\% dari seluruh angket. Jawaban Terampil dengan persentase $42 \%$ dari seluruh angket. Jawaban Kurang Terampil dengan persentase $14 \%$ dari seluruh angket. Sehingga dapat disimpulkan bahwa untuk penilaian psikomotorik kelompok eksperimen B tergolong Sangat Terampil. Untuk kelompok kontrol A engan tingkat keterampilan Sangat Terampil 31\% dari seluruh angket. Jawaban Terampil dengan persentase $55 \%$ dari seluruh angket. Jawaban Kurang Terampil dengan persentase 14\% dari seluruh angket. Sehingga dapat disimpulkan bahwa untuk penilaian psikomotorik kelompok kontrol A tergolong Terampil. Dan untuk kelompok kontrol B dengan tingkat keterampilan Sangat Terampil $30 \%$ dari seluruh angket. Jawaban Terampil dengan persentase 30\% dari seluruh angket. Jawaban Kurang Terampil dengan persentase $40 \%$ dari seluruh angket. Sehingga dapat disimpulkan bahwa untuk penilaian psikomotorik kelompok kontrol B tergolong Tidak Terampil. Dari hasil persentase tersebut makan dapat disimpulkan bahwa pembelajaran PjBL efektif dalam proses penilaian keterampilan (psikomotorik) di Program Studi PTIK STKIP PGRI Pontianak pada matakuliah Pemrograman Visual 1 dilihat dari tingkat keterampilan mahasiswa.

Pembelajaran PjBL pada kelompok eksperimen dapat membantu mahasiswa dalam meningkatkan motivasi belajar, ketelitian, mendorong kemampuan mereka untuk komitmen dalam pengerjaan tugas, dan dapat meningkatkan toleransi dan kerjasama antar mahasiswa. Selain itu, Pembelajaran PjBL dapat meningkatkan kemampuan pemecahan masalah, membuat mahasiswa menjadi lebih aktif dan berhasil memecahkan problemproblem yang kompleks. Hal tersebut dapat dilihat dari hasil analisis penilaian sikap dengan tingkat kesesuaian dan kesetujuan mahasiswa dalam menjawab pernyataan-pernyataan dalam angket penilaian sikap. Hasil analisis kelompok eksperimen A untuk jawaban Sangat Setuju/Sangat Sesuai dengan persentase 19\% dari seluruh angket. Jawaban Setuju/Sesuai dengan persentase $60 \%$ dari seluruh angket. Jawaban Kurang Setuju/Kurang Sesuai dengan persentase $15 \%$ dari seluruh angket. Dan Jawaban Tidak Setuju/Tidak Sesuai dengan persentase $6 \%$ dari seluruh angket. Hasil analisis kelompok eksperimen B untuk jawaban Sangat Setuju/Sangat Sesuai dengan persentase 36\% dari seluruh angket. Jawaban Setuju/Sesuai dengan persentase $44 \%$ dari seluruh angket. Jawaban Kurang Setuju/ Kurang Sesuai dengan persentase 12\% dari seluruh angket. Dan Jawaban Tidak Setuju/ Tidak Sesuai dengan persentase $8 \%$ dari seluruh angket. Hasil analisis kelompok kontrol A untuk jawaban Sangat Setuju/Sangat Sesuai dengan persentase $28 \%$ dari seluruh angket. Jawaban Setuju/Sesuai dengan persentase $51 \%$ dari seluruh angket. Jawaban Kurang 
Setuju/Kurang Sesuai dengan persentase $15 \%$ dari seluruh angket. Dan Jawaban Tidak Setuju/Tidak Sesuai dengan persentase $6 \%$ dari seluruh angket. Hasil analisis kelompok kontrol B untuk jawaban Sangat Setuju/Sangat Sesuai dengan persentase $26 \%$ dari seluruh angket. Jawaban Setuju/Sesuai dengan persentase $52 \%$ dari seluruh angket. Jawaban Kurang Setuju/Kurang Sesuai dengan persentase $17 \%$ dari seluruh angket. Dan Jawaban Tidak Setuju/Tidak Sesuai dengan persentase 5\% dari seluruh angket.

Penerapan pembelajaran PjBL dipandang baik untuk diterapkan, hal ini dapat dilihat melalui hasil analisis angket Penerapan Pembelajaran PjBL. Hal tersebut dapat dilihat dari persentase analisis aspek pembelajaran PjBL yaitu untuk kategori Sangat Baik berjumlah 18\%, untuk kategori Baik berjumlah $76 \%$, untuk kategori Kurang Baik berjumlah $6 \%$, dan untuk kategori Tidak Baik berjumlah $0 \%$. Maka dapat disimpulkan ada penerapan yang baik bagi pengajar dalam proses pembelajaran PjBL di Program Studi PTIK STKIP PGRI Pontianak pada matakuliah Pemograman Visuall.

Hasil pengujian hipotesis yang menyatakan bahwa terdapat perbedaan hasil belajar antara mahasiswa yang diajar dengan pembelajaran PjBL dibandingkan mahasiswa yang diajarkan dengan pembelajaran konvensional dengan metode tutorial. Hal ini dapat dilihat dengan nilai rata-rata posttest. Nilai rata-rata posttest kelompok eksperimen A 44,9722, kelompok eksperimen B 42,4722, kelompok kontrol A 40,5556, dan kelompok kontrol B 37,5882. Pada tabel hasil One-Way Anova didapatkan nilai kuadrat antar kelompok sebesar 1020.086 dengan rata-rata kuadrat 340,029. Jumlah kuadrat diantara kelompok 11339,069 dengan rata-rata kuadrat 82,167. Besar $\mathrm{F}$ hitung adalah 4,138 dengan signifikan 0,001. Dengan ketentuan yang digunakan apabila $\mathrm{F}$ hitung lebih besar dari $\mathrm{F}$ tabel maka hipotesis diterima, dari hasil penelitian diperoleh $\mathrm{F}$ hitung 4,138 sedangkan nilai $\mathrm{F}$ tabel dengan taraf kesalahan 5\% adalah 2,67. Dari perbandingan nilai tersebut didapatkan bahwa nilai $\mathrm{F}$ hitung $>\mathrm{F}$ tabel yaitu 4,138>2,67 sehingga hipotesis diterima. Sedangkan untuk nilai taraf signifikan dengan hasil $\alpha=0,008<0,05$. Maka dapat disimpulkan bahwa terdapat efektifitas penerapan model pembelajaran PjBL di Program Studi PTIK STKIP PGRI Pontianak pada mata kuliah Pemograman Visual 1 dalam meningkatkan hasil belajar mahasiswa.

Berdasarkan hasil uji deskriptif dan uji hipotesis maka dapat diketahui bahwa pembelajaran PjBL efektif diterapkan untuk meningkatkan hasil belajar mahasiswa. Hal ini berdasarkan bahwa peneliti melakukan tahapan-tahapan PjBL yang sesuai dengan refrensi yang ada. Pelaksanaan tahapantahapan PjBL dari tahapan perencanaan sampai menampilkan hasil proyek aplikasi berjalan dengan baik. Dalam proses pelaksanaan pembelajaran $\mathrm{PjBL}$ didukung dengan adanya laboratorium komputer yang memadai dan mahasiswa dapat bekerja sama dengan baik dalam proses pembelajaran. Pelaksanaan pembelajaran PjBL dengan matakuliah Pemrograman Visual 1 memberikan dampak yang positif bagi mahasiswa. Hal tersebut dapat dilihat dari ketertarikan mahasiswa terhadap matakuliah tersebut. Pemrograman Visual 1 merupakan matakuliah yang memberikan inovasi dan motivasi kepada mahasiswa dalam mengikuti dan memprkatikan matakuliah tersebut khususnya pada kerja proyek aplikasi.

Penerapan pembelajaran $\mathrm{PjBL}$ pada penelitian ini dapat dikatakan baik dan berhasil, hal tersebut juga dapat didukung dengan penelitian yang relevan yang dilakukan oleh Susriyati Mahanal, Ericka Darmawan, A.D. Corebima, dan Siti Zubaidah dalam judul Pengaruh Pembelajaran Project Based Learning (PjBL) pada Materi Ekosistem terhadap Sikap dan Hasil Belajar Siswa SMAN 2 Malang. Penelitian tersebut bertujuan untuk mengetahui pengaruh Pembelajaran Project Based Learning (PjBL) terhadap sikap dan prestasi kognitif siswa di SMAN 2 Malang. Hasil dari penelitian ini menunjukkan bahwa ada pengaruh $\mathrm{PjBL}$ terhadap prestasi kognitif dan sikap siswa terhadap ekosistem sungai. Siswa dengan PjBL memiliki sikap yang lebih tinggi $11,65 \%$ dari siswa konvensional. Selain itu, siswa dengan $\mathrm{PjBL}$ memiliki prestasi kognitif yang lebih tinggi $81,05 \%$ dari mahasiswa konvensional. 


\section{SIMPULAN DAN SARAN}

\section{Simpulan}

Model pembelajaran PjBL lebih efektif dalam meningkatkan hasil belajar mahasiswa di Program Studi PTIK STKIP PGRI Pontianak pada mata kuliah Pemrograman Visual 1 dibanding model pembelajaran konvensional dengan metode tutorial. Hal tersebut dapat dilihat dengan nilai rata-rata posttest. Hal ini dapat dilihat dengan nilai rata-rata posttest. Nilai rata-rata posttest kelompok eksperimen A 44,9722, kelompok eksperimen B 42,4722, kelompok kontrol A 40,5556, dan kelompok kontrol B 37,5882. Pada tabel hasil One-Way Anova didapatkan nilai kuadrat antar kelompok sebesar 1020.086 dengan rata-rata kuadrat 340,029 . Jumlah kuadrat diantara kelompok 11339,069 dengan rata-rata kuadrat 82,167. Besar $\mathrm{F}$ hitung adalah 4,138 dengan signifikan 0,001 . Dengan ketentuan yang digunakan apabila $\mathrm{F}$ hitung lebih besar dari $\mathrm{F}$ tabel maka hipotesis diterima, dari hasil penelitian diperoleh $\mathrm{F}$ hitung 4,138 sedangkan nilai $\mathrm{F}$ tabel dengan taraf kesalahan 5\% adalah 2,67. Dari perbandingan nilai tersebut didapatkan bahwa nilai F hitung $>$ F tabel yaitu 4,138 $>2,67$ sehingga hipotesis diterima. Sedangkan untuk nilai taraf signifikan dengan hasil $\alpha=0,008<0,05$. Maka penerapan pembelajaran PjBL dapat dikatakan efektif pada mata kuliah Pemrograman Visual 1 di Prodi PTIK STKIP PGRI Pontianak. Sedangkan aspek penilain proyek dapat dilihat bahwa untuk nilai taraf signifikan penilaian proyek dengan hasil $\alpha=0,001<0,05$. Maka dapat disimpulkan penerapan model pembelajaran $\mathrm{PjBL}$ lebih efektif dalam penilaian tugas proyek mahasiswa di Program Studi PTIK STKIP PGRI Pontianak dibanding model pembelajaran konvensional dengan metode tutorial

\section{Saran}

Proses pembelajaran pada mata kuliah Pemrograman Visual 1 dengan menggunakan pembelajaran Project Based Learning dapat berjalan dengan baik dan menambah pengalaman bagi para mahasiswa dan pengajar. Untuk dapat mengembangkan hasil belajar yang telah dicapai dalam penelitian ini, maka peneliti memliki beberapa saran:
(1) pembelajaran PjBL lebih baik diterapkan pada setiap matakuliah yang berkaitan dengan pembelajaran praktik agar mahasiswa lebih mandiri dalam menghadapi masalah; (2) agar mahasiswa menghasilkan karya kontekstual baik individual maupun kelompok maka sangat disarankan menggunakan pendekatan pembelajaran yang menghasilkan karya berbasis proyek (Project Based Learning); (3) untuk penilaian proyek yang dilakukan oleh seorang pendidik, seharusnya penilaian dilakukan setiap akhir Bab atau tema pelajaran; (4) pembelajaran PjBL lebih baik diterapkan pada setiap progam studi dan kelas dalam satu lembaga pendidikan; (5) pembelajaran PjBL lebih baik diterapkan selama 1 semester dalam proses pembelajaran. Agar lebih meningkatkan hasil belajar mahasiswa secara maksimal.

\section{DAFTAR PUSTAKA}

Arifin, Z. (2009). Evaluasi pembelajaran, prinsip, teknik dan prosedur. Bandung: Remaja Rosdakarya.

Asep Jihad. (2009). Evaluasi pembelajaran. Yogyakarta: Multi Pressindo.

Barell, J. (2010). Problem based learning: The Foundation for 21st century skills. In J. Ballanca \& R. Brandt (Eds.), 21st century skills: Rethinking how students learn. Bloomington, IN: Solution Tree Press.

Baron, K. (2011). Six steps for planning a successful project. Retrieved on March 29, 2011, from www.edutopia. org/maine-project-learning-six-stepsplanning

Bender, W.N. (2012). Project based learning. Differentiating intruction for the 21st century. California: Corwin.

Bloom, B.S. (2001). Taksonomi of educational objektif, Hand Book 1, Cognitive Domain. New York: Longman

Burden, P.R., \& Byrd, D.M. (1999). Method for effective teaching, Second Edition. Boston: Allyn and Bacon 
Cole, J.E, \& Washburn-Moses, L. H. (2010). Going beyond "the math wars". A special educator's guide to understanding and assisting with inquiry-based teaching in mathematics. Teaching Exceptional Children, 42 (4), 14-21.

Cote, D. (2007). Problem based learning software for student with disabilities. Intervention in school and clinic, 43(1), 29-37.

Dahar, R. W. (1998). Teori-teori belajar. Jakarta : Erlangga.

Djamarrah, S.B. \& Zain, A. (2002). Strategi belajar mengajar. Jakarta : Reneka Cipta.

Doppelt, Y. (2003). Implementation and assesment of project based learning in a flexible environment. International Journal of Technology and Design Education. Netherlands: Kluwer Academic Publishers.

Dopplet, Y. (2005). Assesment of project based learning in a metchatronics Context. Journal of Technology Education Vol.16 No.2, Spring 2005.

Gagne, Robert M., \& Briggs, Leslie J. (1979). Principles of intructional design. (2 nd ed). New York : Holt, Rinenart and Winston.

George Lucas Educational Foundation. (2001). Project based learning research. edutopia. www.edutopia.org

Grant, M.M. (2010). Getting a grip on ptojectbased learning: Theory, cases and recommendations. From www.nscu.edu/ meridian/winn2002/514/3.html

Gunter, M. A., Estes, T. H., \& Schwab, J. H. (1990). Instruction: A models approach. Boston: Allyn and Bacon.

Gulo, W. (2004). Strategi belajar mengajar. Jakarta: Grasindo.

Hamilik, O. (2003). Kurikulum pembelajaran. Jakarta: Bumi Askara.
Hamalik, O. (2003). Media pendidikan. Bandung: PT. Cipta Adiya Bakti.

Herminato Sofyan. (2001). Pengaruh strategi pembelajaran dan gaya berpikir siswa terhadap hasil belajar motor otomotif. Desertasi. Jakarta : Universitas Negeri Jakarta.

Jonassen, D.H. (1997). Intructional design models for well-structured and Illstructured problem solving learning outcomes. Educational Technology Research and Development 45. New York: Springer.

Joyce \& Weil. (1980). Model of teaching. Engalewood Cliffs. New Jersey: Prientice-Hall, Inc.

Land, S.M., \& Green, B.A. (2000). Project based learning with the world wide web: A qualitative study of resource integration. Educational Technology Research and Development, 48(1), 45-67.

Larmer, J., \& Mergendoller, J.R. (2010). 7 Essentials for project based learning. Educational Leadership, 68(1), 34-37

McMillan, J.H., \& Schumacher, S. (2010). Research in education evidance-based inquiry (7 th ed). Pearson.

Miarso, Y. 2004. Menyemai benih teknologi pendidikan. Jakarta: Kencana.

Moore, Kenneth D. (2009). Effective intructional srategies : from theory of practice (2 nd ed). London : SAGE Publication, Inc

Nazir, M. (2005). Metode penelitian. Bogor : Ghalia Indonesia.

Oakley L.D. (1998). Social cultural context of phsyciatric nursing, sixth edition, Philadelphia: Mosby Year Book Inc.

Rusman. (2012). Belajar dan pembelajaran berbasis komputer: Mengembangkan profesionalisme guru abad 21. Bandung: Alfabeta. 